Federal Reserve Bank of Minneapolis

Research Department Staff Report 269

April 2000

\title{
The Scale of Production in Technological Revolutions
}

\author{
Matthew F. Mitchell* \\ Federal Reserve Bank of Minneapolis \\ and University of Minnesota
}

\begin{abstract}
Many manufacturing industries, including the computer industry, have seen large increases in productivity growth rates and have experienced a reduction in average establishment size and a decrease in the variance of the sizes of plants. A vintage capital model is introduced where learning increases productivity on any given technology and firms choose when to adopt a new vintage. In the model, a rise in the rate of technological change leads to a decrease in both the mean and variance of the size distribution.

*Thanks to April Franco, Gautam Gowrisankaran, Tom Holmes, Hugo Hopenhayn, Boyan Jovanovic, and Glenn MacDonald for very helpful comments. Grateful acknowledgment is given to funding from NSF grant SBR-9809530. The views expressed herein are those of the author and not necessarily those of the Federal Reserve Bank of Minneapolis or the Federal Reserve System.
\end{abstract}




\section{Introduction}

The relationship between the scale of production and the rate of innovation is a classic issue in the study of the organization of industry. A large body of research (Scherer (1980), Acs and Audretsch (1990), and others) has approached the problem from the standpoint of how the size of an enterprise affects innovation. Less attention has been focused on the other channel, that is, that the rate of arrival of new technologies might affect the scale of production across producers.

In this paper, a theory is introduced where an exogenous increase in the rate of technological progress leads to smaller plants and a more concentrated size distribution. The increase in technological change can be thought of as a technological revolution. In manufacturing industries from 1977 to 1994, as well as in the particular case of the computer industry (SIC 3573), that pattern emerges in the data: industries which go from low to high growth tend to have the mean and variance of their establishment size distribution shrink. Technological revolutions lower the scale of production and reduce the variability of plant size.

In order to capture this, a model is introduced which has two important ingredients: a vintage structure to technology and gradual learning at the plant level about a given vintage. Increased total factor productivity (TFP) growth comes from improvements in technology. Each establishment has a given vintage of technology and a level of experience on that vintage. The crucial feature is the differing incentive to adopt faced by incumbents of various ages. Evidence of significant plant and machine turnover and replacement suggests that retooling is a very important part of plant evolution. There is substantial evidence of investment spikes at experienced plants (Doms and Dunne (1998)), and these spikes are often thought of as 
instances of retooling. The rate of technological progress clearly affects when technologies are adopted when progress is embodied in capital, since the opportunity cost of using an old technology is high when progress is fast.

To counteract the incentive to constantly upgrade technology, it is assumed that producers accumulate knowledge about a given vintage of technology as they use it. A long tradition of studies suggests that learning by doing is an important element of production (see Argote and Epple (1990) for a review). The learning on any given vintage is bounded, up to some maximum productivity possible under that technology. Eventually, plants must adopt a new technology in order to compete with plants near the frontier.

The model is used to predict how the size distribution of plants is related to the rate of technological progress. For a fixed distribution of vintages, rapid change increases the variability of size, since the difference between a frontier technology and a backward technology is magnified. However, when change is rapid, new technologies bring large increases in productivity, causing establishments to adopt more frequently. The result is that the technologies chosen are bunched near the technological frontier, a force toward less variability in establishment size. In terms of average size of plants, the effects are more subtle. It is shown, in fact, that when the future is not discounted, there is no effect, and when agents are myopic, there are two countervailing effects. In the numerical results, though, where the discount factor is between zero and one, the force toward smaller plants is dominant.

An interesting case of a change in the rate of technological progress is that of the computer industry. Semiconductor main memory was introduced in 1971 and greatly increased the speed of computers (Dulberger (1989)). The change translated into an increased rate of technological progress. Figure 1 displays the yearly TFP growth rate, calculated as a Solow 
residual in a multifactor production function, for the computer industry, SIC 3573 (Electronic Computing Equipment), in the United States. ${ }^{1}$ There is a marked rise in the growth rate of TFP in the early 1970s, when this revolution began.

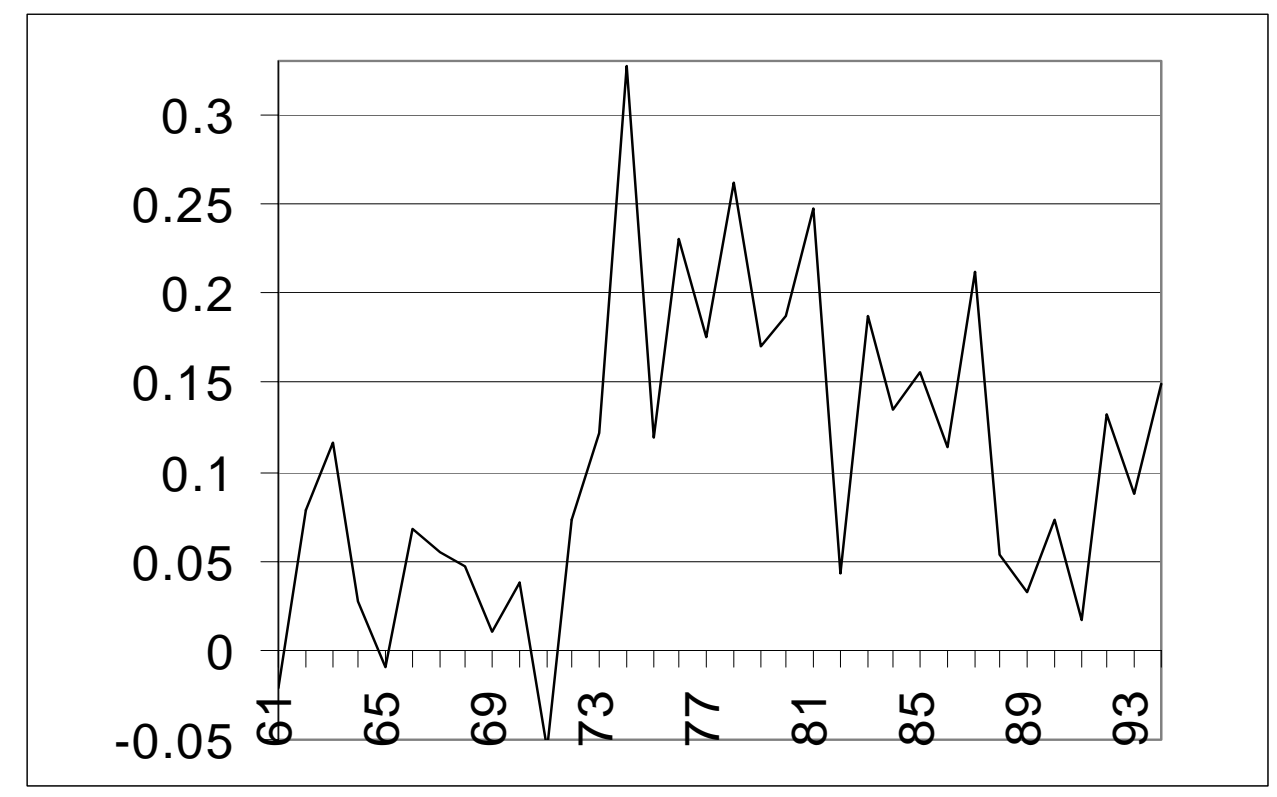

TFP Growth, SIC 3573

The scale of production, as measured by employees per plant, also changed. Computer establishments tended to be smaller, and the variability of the sizes of establishments was reduced as time passed following the revolution. These changes for 3573 are summarized

\footnotetext{
${ }^{1}$ The data are from the NBER TFP database, which is discussed in Bartelsman and Gray (1996).
} 
below. ${ }^{2}$

$\begin{array}{ccc}\text { Year } & \text { Mean Plant Size } & \text { St.Dev. of Plant Size } \\ 72 & 290 & 641 \\ 77 & 261 & 602 \\ 82 & 228 & 558 \\ 87 & 197 & 526 \\ 92 & 127 & 399\end{array}$

The data are for census years. The size distribution of plants has, in fact, nearly monotonically declined (in the sense of first-order dominance of the distribution) in each census year, suggesting a pervasive change in the mean. ${ }^{3}$ The decline in the standard deviation of the distribution of sizes has also been dramatic.

One way to reconcile the relationship between average size and productivity is if capital is simply substituting for labor. The substitute theory is problematic, however. One problem is that, if TFP growth rises due to embodied technological change and plants respond by substituting capital for labor, output per worker should increase dramatically, faster than TFP. In fact, output per worker has, in the case of 3573 , risen much less sharply than TFP. ${ }^{4}$ Complementarity between capital and labor is a common feature of the many technologies which have been used, and it will be maintained in this paper.

There is evidence of the same relationship between the rate of technological progress and the size distribution beyond the computer industry example. The following section doc-

\footnotetext{
${ }^{2}$ Since only plant count by employment class is disclosed, it is impossible to measure the variance exactly. These calculations assume that each plant within a size category is at the average size across manufacturing industries for that category.

${ }^{3}$ That fact cannot, of course, be determined from the statistics reported.

${ }^{4}$ This is similar to the picture of the macroeconomy, where labor productivity growth has slowed, while embodied technological change has, if anything, increased (Greenwood and Yorukoglu 1997).
} 
uments several facts for U.S. manufacturing establishments over the time period of 1977 to 1994. Industries which experience dramatic increases in the rate of growth of TFP, like the computer industry, are compared to the rest of the sample, which had no such "revolution." The industries which experienced a revolution saw average establishment size fall dramatically. These same industries also saw significant reduction in the variability of their establishment size distribution. The set of industries undergoing the change include many high-technology industries, one of which seem a very plausible candidate for the view that there has been a fundamental change in the rate of technological progress.

The theory promoted here can account for both the size and the variance change in the distribution. This suggests that not only might size be an important determinant of innovative activity, as many papers have focused on, but also it may be the case that the rate of change affects the scale of operation.

Several recent papers (for instance, Greenwood and Yorukoglu (1997) and Greenwood and Jovanovic (1999)) suggest that the entire U.S. economy is going through a technological revolution. To be sure, the mean and variance of manufacturing plant sizes have been falling (Baily et al. (1996)). This paper does not take a stand on the issue of an economywide revolution, but it is suggestive, in the sense that the overall changes in the establishment size distribution coincide with the dates that authors have suggested as the dawn of this economywide revolution.

Section 3 introduces the model, which combines vintage capital into an aggregate model of many competitive industries, each with entry and exit. The main tenet of the model is that the plant stores information about how to efficiently operate a technology. Plants act as Bayesian decision makers who have information which is retained from period 
to period. Changing vintages involves the loss of some of the useful information. The vintagespecificity of knowledge serves as a cost of changing vintages. As opposed to a pure fixed cost, however, the loss of information lowers marginal product during the accumulation of new knowledge. It is shown that a fixed cost will have the inverse prediction for the size distribution compared to the theory presented here.

When a plant first enters, it has limited information about how to produce. It adopts a technology and undertakes production. As it produces, it generates information which makes it more efficient. If it chooses to adopt a new technology, it gains productivity because new technologies are more productive, but it loses productivity due to lost knowledge. In order to capture these effects and their effect on plant behavior, a model with many successive technologies is introduced. Information's role in production is formalized with a Bayesian learning structure along the lines of Jovanovic and Nyarko (1996). Each plant has a vintagespecific parameter which reflects the best way to produce. Each period, the producer chooses a method of production and, from the outcome of the production process, learns a bit more about the best way to operate the technology.

Unlike Jovanovic and Nyarko's work, the technologies will be operated by a continuum of forward-looking agents in a competitive environment. In order to keep the analysis tractable, however, the parameters and forms used will be significantly less rich. Jovanovic and Nyarko (1996) analyze a single, myopic agent, but compare across a wide variety of parameters. Here, comparative statics on a single parameter, the rate of technological progress, holding others fixed, is the focus. Section 4 calibrates the model to learning curve data and shows that an increase in the rate of technological progress makes small establishments relatively more prevalent, while decreasing the total variance of plant sizes. 


\section{Industry Productivity Growth and the Size of Establishments: Evidence from U.S. Manufacturing}

The computer industry is just one example of the relationship between technological change and the size distribution. A more complete picture can be attained by studying size distributions from the U.S. Census' County Business Patterns, combined with productivity data from the NBER TFP Database for each manufacturing SIC and each year from 1977 to $1994 . .^{5}$

Two important features of the recent evolution of the manufacturing size distribution are the decreases in both the mean size and size variability for U.S. manufacturing establishments (see Baily et al. (1996)). The forces behind these changes are an important issue for understanding the organization of industry and are studied in detail in Gowrisankaran and Mitchell (2000). Here, the focus is not on the overall trend. Instead, I look to see if industries that underwent large increases in the rate of technological change (what might be termed a technological revolution) also had predictable changes in the size distribution.

In order to determine which industries had the biggest changes in the rate of technological progress, a trend line is fitted to the growth rate of TFP, denoted $T_{t}$, for each industry. This estimated trend for industry $i$ is denoted $\beta_{i}^{T}$ :

$$
T_{i, t}=\alpha_{i}^{T}+\beta_{i}^{T} t+\varepsilon
$$

The industries are ranked according to this parameter. Extreme values in terms of $\beta_{i}^{T}$ are the industries which are thought of as having undergone a revolution.

\footnotetext{
${ }^{5}$ The choice of dates reflects years for which size distributions are readily available in an electronic format from the U.S. Census' County Business Patterns.
} 
In order to measure change in the mean and variability of the size distribution, trend lines are fitted for each industry for the logarithm of mean establishment size (with resulting parameter $\left.\beta_{i}^{S}\right)$ and the logarithm of the standard deviation of the size distribution $\left(\beta_{i}^{V}\right)$. Mean size is calculated simply using total employees divided by total establishments. Calculating the standard deviation requires the entire distribution, which is not reported for every size category and every year. Therefore the following strategy is adopted. For each industry, for each year, for each size category, total establishments are reported, but total employment may not be. ${ }^{6}$ A measure of employment is constructed using the figures for total establishment and the average employment in the overall sample for each size class. Consistent with much of the literature, the standard deviation is calculated weighting each size class by its employment. This ensures that the changes are not coming about due to changes of a few establishments in very small employment categories.

An attempt was made to estimate a lognormal distribution (using maximum likelihood) to each of the industries' size distributions in each year. Unfortunately, while the lognormal does fit the overall size distribution and some large industries rather well, it was very inappropriate (for instance, its predictions for the mean were dramatically inaccurate) for a large fraction of the industries. As a result, the more simple-minded approach outlined above was followed.

According to the theory, we focus on the comparison between the industries increasing rapidly in technological change (the top quartile of the estimate $\beta_{i}^{T}$ ) and the rest of the industries. The results are presented below.

\footnotetext{
${ }^{6}$ This is done to ensure anonymity of the employment level of individual plants when there are only a few plants in a given size category.
} 
Average of: Top quartile Other industries

$\begin{array}{ccc}\beta_{i}^{S} & -0.029 & -0.017 \\ \beta_{i}^{V} & -0.100 & -0.048 \\ \beta_{i}^{T} & 0.014 & 0.000\end{array}$

All of the differences are significant at the $95 \%$ level. Industries which experienced a speed-up in technological progress saw faster than normal declines in both the size of establishments and the concentration of establishment size. Both are economically important, as well. Whereas the size of the industries in the top quartile is falling at about three percent per year, it is falling at less than two percent for other industries. More strikingly, the reduction in variance is more than double - the industries with fast change are reducing variance by ten percent per year.

When the top group is taken to be the top $5 \%$ or $10 \%$ of $\beta_{i}^{T}$, the differences are even larger, as one would expect. If one focuses on the bottom-ranked industries in terms of $\beta_{i}^{T}$, the relationship also holds: the industries whose technological change has slowed significantly have significantly less reduction in average size and variability than do the rest. The result is less striking, though, because while the top of the $\beta_{i}^{T}$ distribution is substantially different from the rest, the bottom is not nearly so far from the average increase in technological progress. It happens that, in the sample, we see more industries undergoing "technological revolutions" in terms of TFP than we do industries where the revolution seems to be ending.

One way to summarize the relationships is through correlations between the trend coefficients. Since technological change is related to the size of establishments, it might be that the level of technology is also relevant. Denote by $\bar{T}_{i}$ the average rate of technological 
progress in industry $i$. The following table reports correlations between variables $\left(^{*}\right.$ denotes significant at the $95 \%$ level):

$$
\begin{array}{ccc}
\sigma_{x y} & \beta_{i}^{T} & \bar{T}_{i} \\
\beta_{i}^{S} & -0.15^{*} & -0.05 \\
\beta_{i}^{V} & -0.24^{*} & -0.09
\end{array}
$$

Notice that the level of productivity growth is not significantly correlated with changes in either size or variability, but the change in TFP growth is negatively correlated with both. ${ }^{7}$ The model will have the feature that the size distribution is constant over time for a constant rate of technological progress. Changes to the size distribution will come about exclusively as a result of shocks to the rate of growth of technological progress as, for instance, was experienced in the early 1970s by SIC 3573, since it is those changes that are connected to the changes in the size distribution for U.S. manufacturing industries.

Note that even the industries with $\beta_{i}^{T}$ around zero, i.e., which have no change in their growth rate of TFP, had falling mean and variance for size. The model will not be able to capture that fact; evidently, there is another force lowering plant size and variability. However, it is clear that the top group is substantially different from the rest, and that is what the model seeks to explain.

\section{The Model}

A. Production at the Plant The Production Function

Consider a plant in a discrete time, infinite horizon industry populated by a continuum of competitive establishments and facing a sequence of prices $p_{t}$, where $p$ is the output

\footnotetext{
${ }^{7}$ Moreover, partial correlations confirm that the contribution of $\bar{T}$ is not significant for either $\beta_{i}^{S}$ or $\beta_{i}^{V}$.
} 
price of the homogeneous product the industry produces and the interest rate is $r$. Production occurs at individual plants. Consumers, other industries, and the resulting equilibrium determination of price will be studied in the following subsections.

Each period a new technology for producing the product arrives. Along the lines of recent work by Greenwood et al. (1997), new vintages of technology cannot be combined, but rather the adoption of a new technology involves the scrapping of the old. ${ }^{8}$ The technological vintage $v$ denotes the time period in which it first becomes available. The plant's efficiency at using its technology is summarized by $\lambda_{t} \leq 1$. The level of $\lambda$ can be thought of as the amount of organizational capital the plant has. When $\lambda_{t}=1$, the plant is operating the capital at maximum efficiency. The output of an establishment with efficiency level $\lambda_{t}$, which employs $l_{t}$ units of labor, is

$$
f_{v}\left(l_{t} ; \lambda_{t}\right)=\lambda_{t} \gamma^{v} l_{t}^{\alpha} .
$$

The plant has decreasing returns $(\alpha<1)$ to hiring the single factor, labor $l$. Labor is variable in each period. Creating a new establishment requires the payment of a fixed entry cost, E. The fixed cost paid for entry can be thought of as the cost of capital. It is straightforward to explicitly add capital to the analysis and have the growth effect come through increased efficiency of new vintages of capital. It adds substantially to the notation, though, without affecting the results of interest.

\footnotetext{
${ }^{8}$ The model can easily accommodate the firms' operating more than one technology simultaneously, so long as there is a cost to operating multiple technologies. Without such a cost, firms will operate all of the technologies simultaneously.
} 


\section{Information and the Evolution of Organizational Capital}

To formalize the role of information in production, a plant will be assumed to draw its own technology-specific unknown parameter $\theta_{v}$. The plant's efficiency $\lambda_{t}$ is given by

$$
\lambda_{t}=\left[\bar{\lambda}-\left(\theta_{v_{t}}+\varepsilon_{t}-q_{t}\right)^{2}\right]
$$

where $\bar{\lambda}$ is a normalizing constant. As in Jovanovic and Nyarko (1996), ${ }^{9}$ the plant chooses $q_{t}$. It makes this choice given beliefs $\mu_{t}$ about $\theta$, and then a normally distributed, mean zero, independent shock $\varepsilon_{t}$ strikes the plant. The choice of $q_{t}$ will be termed a "production technique," since this choice affects the productivity of the plant, but will otherwise be costless to implement. The full-information optimal production technique is precisely the unknown parameter $\theta$.

As in Jovanovic and Nyarko (1996), the plant will be assumed to observe $\theta+\varepsilon$ costlessly each period. ${ }^{10}$ Suppose that the unconditional distribution of $\theta$ from which each plant draws is a normal distribution with variance $\sigma_{0}^{2}$. Denote the variance of $\varepsilon$ by $\sigma_{\varepsilon}^{2}$. Bayes' Rule will imply beliefs $\mu$ that are normally distributed and therefore can be summarized by the mean $\bar{\mu}$ and variance $\sigma_{\mu}^{2}$. Because the information generated in each period is independent of the establishment's decisions, optimality dictates that plants set $q=\bar{\mu}$. Expected capital efficiency, then, is

$$
\left[\bar{\lambda}-\left(\sigma_{\mu_{v}}^{2}+\sigma_{\varepsilon}^{2}\right)\right]
$$

By way of normalization, let $\bar{\lambda}=1+\sigma_{\varepsilon}^{2}$. Since the establishment is risk neutral, henceforth

\footnotetext{
${ }^{9}$ See also earlier work by Prescott (1972) and Wilson (1975).

${ }^{10}$ This is with only a slight loss of generality, as $|\theta+\epsilon|$ can be inferred from observing the firm's output.
} 
define $\lambda_{t}$ to be expected efficiency

$$
\lambda_{t}=1-\sigma_{\mu}^{2}
$$

Notice that expected efficiency is independent of the plant's expected $\theta$ given by $\bar{\mu}$, and therefore we can focus only on the variance of the beliefs in formulating the plant's problem.

Experience will affect the plant's variance $\sigma_{\mu_{v}}^{2}$ for technology $v$. In particular, the variance evolves according to the updating rule $\sigma_{\mu_{v}, t+1}^{2}=h\left(\sigma_{\mu_{v}, t}^{2}, \sigma_{\varepsilon}^{2}\right)$, where

$$
h\left(\sigma_{\mu_{v}}^{2}\right)=\frac{\sigma_{\mu_{v}}^{2} \sigma_{\varepsilon}^{2}}{\sigma_{\mu_{v}}^{2}+\sigma_{\varepsilon}^{2}} .
$$

New vintages produce more output $(\gamma>1)$. When a new vintage is used, a new $\theta_{v^{\prime}}$ is drawn from a distribution with variance $\sigma_{0}^{2}$, which is then the variance of the plant's beliefs. Since this is identical across vintages, a plant will always upgrade to the frontier vintage.

\section{The Plant's Problem}

To sum up the previous analysis, static profits as a function of vintage and uncertainty about $\theta$ can be reduced to

$$
\pi_{t}\left(v, \sigma_{\mu}^{2}\right)=\max _{l \geq 0}\left\{p_{t} \gamma^{v}\left[1-\sigma_{\mu_{v}}^{2}\right] l^{\alpha}-l\right\}
$$

Labor is chosen according to a static first order condition, since labor input does not affect the amount of information produced. Letting the wage rate be the numeraire in the spot market at time $t$, the optimal choice of labor $l^{*}\left(\sigma_{\mu_{v}}^{2} ; p\right)$ is

$$
l^{*}\left(v, \sigma_{\mu_{v}}^{2} ; p\right)=\left(\alpha p_{t} \gamma^{v}\left[1-\sigma_{\mu_{v}}^{2}\right]\right)^{1 /(1-\alpha)}
$$


Note that $\bar{\mu}_{v}$ does not affect the plant's expected output or labor choice in the reduced form in (4) or (5) and need not be discussed from this point forward.

The dynamic program of the plant which discounts the future by $\frac{1}{1+r}$ is given by

$$
V_{t}\left(v, \sigma_{\mu}^{2}\right)=\pi_{t}\left(v, \sigma_{\mu}^{2}\right)+\frac{1}{1+r_{t}} \max \left\{V_{t+1}\left(t+1, \sigma_{0}^{2}\right), V_{t+1}\left(v, h\left(\sigma_{\mu}^{2}\right)\right)\right\} .
$$

The plant can choose to upgrade to the vintage $t+1$ technology and have uncertainty $\sigma_{0}^{2}$ or stay with vintage $v$ and have variance updated according to $h$.

\section{Industry Growth}

First consider one industry in isolation, as if it faced a given set of prices. The industry faces a fixed wage $w$, a constant interest rate $r$, and a series of prices $p_{t}=\gamma^{-t} p_{0}$ for the plant's output. This will allow for a very simple sort of "balanced growth": constant size distribution of establishments (relative to the frontier and measured by employment), rising output per establishment, $Q$ rising at rate $\gamma$, and $p$ falling at rate $\gamma$. In addition, it turns out that such a price and output sequence will be consistent with general equilibrium for the economy to be outlined below.

Along this path, $p_{t} \gamma^{t}$ is the constant $p_{0}$, and we can write a stationary dynamic program in place of (6). Let $b=t-v$, the number of vintages behind the frontier the plant finds itself. Denote by $h^{n}\left(\sigma_{\mu}^{2}\right)$ the composition of the function $h$ applied $n$ times to $\sigma_{\mu}^{2}$. Then profits can be described by

$$
\hat{\pi}(b)=\max _{l \geq 0}\left\{p_{0} \gamma^{-b}\left[1-h^{b}\left(\sigma_{0}^{2}\right)\right] l^{\alpha}-l\right\} .
$$

We have the following transformed problem: 


$$
W(b)=\hat{\pi}(b)+\frac{1}{1+r} \max \{W(0), W(b+1)\} .
$$

The transformed problem is stationary. A plant uses a vintage up to some critical $b^{*}$, at which point it upgrades to the frontier. We consider a stationary distribution of plants across vintages, i.e., an identical measure of plants across each vintage up to $b^{*}$. If there are $M$ establishments of each vintage in operation, aggregate quantity produced by the industry at time $t$ is

$$
Q_{i t}\left(b^{*}, M\right)=M \sum_{b=1}^{b^{*}} \gamma^{t-b}\left[1-\sigma_{\mu_{v}}^{2}\right]\left(l^{*}\left(t-b, h^{b}\left(\sigma_{\mu}^{2}\right)\right)\right)^{\alpha}
$$

Since any plant can enter at any time, free entry requires that $W(0)=E$, the cost of entry.

\section{B. The Aggregate Economy}

\section{The Household}

A representative household consumes output and supplies labor. The household has preferences over a large number of consumption commodities, each produced by a separate industry. The household has time separable preferences with discount factor $\delta$ and instantaneous utility

$$
u(c)=\int_{0}^{1} \log c_{i} d i
$$

where $c=\left\{c_{i}\right\}$ is the profile of consumption across goods. Leisure does not enter; a time endowment of one unit is suppled inelastically. The number (measure) of products is normalized to one. ${ }^{11}$

\footnotetext{
${ }^{11}$ If one wished to add an elastic labor supply, the important restriction to maintain balanced growth would be that a constant labor supply is achieved for a constant wage and interest rate and an output price falling
} 
The consumer's budget constraint is

$$
\sum_{t=0}^{\infty} R_{t}\left(\int_{0}^{1} p_{i t} c_{i t} d i\right)=\sum_{t=0}^{\infty} R_{t}\left(w_{t}+\Pi_{t}\right)
$$

The final part of the consumer's budget constraint is profits $\Pi_{t}$ from the plants, which will be zero in equilibrium. The term $R_{t}$ is cumulative, discounting to $t, \prod_{i=0}^{\infty} \frac{1}{1+r_{i}}$.

\section{Balanced Growth Equilibrium}

Equilibrium requires that agents optimize and markets clear. Formally,

(1) Agents Optimize: $\left\{c_{i t}\right\}_{t=0}^{\infty}$ maximizes (9) subject to (10).

(2) Optimal Choice of Vintage: $b^{*}$ solves the production problem in (8).

(3) Free Entry: $W(0)=E$.

(4) Markets Clear: $Q_{i t}\left(b^{*}, M\right)=c_{i t} \forall i, t$.

Suppose that output from each industry grows at the rate $\gamma_{i}$. Consider the following candidate balanced growth steady state. Wages are constant. The output price for industry $i$ in the spot market at time $t, p_{i t}$, falls at the rate $\gamma_{i}$. The one period interest rate $1+r_{t}$ is constant and equal to $\frac{1}{\delta}$.

In this case, the Euler equation for the consumer, in terms of good 0, can be solved for a consumption sequence that grows at rate $\gamma_{0}$. That first order condition is

$$
\frac{1}{p_{0 t} c_{0 t}}=\frac{\delta\left(\frac{1}{1+r_{t}}\right)}{p_{0, t+1} c_{0, t+1}}
$$

at a constant rate. 
The left hand side is the marginal value, in terms of good 0 , of one unit of the numeraire (labor) at time $t$, and the right side is that marginal value at time $t+1$. Replacing $\frac{1}{1+r_{t}}$ with $\frac{1}{\delta}, p_{0, t+1}=\gamma_{0}^{-1} p_{0, t}$, and $c_{0, t+1}=\gamma_{0} c_{0 t}$ satisfies the equation.

The first order condition for consumption of good $i$, given that $c_{t}$ and $p_{t}$ are the consumption and prices of the other goods, is

$$
c_{i t} p_{i t}=c_{0 t} p_{0 t}
$$

In the steady state equilibrium described, $c_{t} p_{t}$ is a constant $c_{0} p_{0}$. As a result, one can view industry $i$ as facing a constant reduced demand

$$
p_{i t}=\frac{c_{0} p_{0}}{c_{i t}}
$$

For market clearing in industry $i, Q_{i t}=c_{i t}$. Since $Q_{i t}$ rises at rate $\gamma_{i}$ when $p_{i t}$ falls at the same rate, the condition can be satisfied for the sort of growth path described in the last section. Relative to industry 0 , prices fall and quantities rise at rate $\gamma_{i} / \gamma_{0}$. The size distribution is constant, as the plant's problem can be rewritten in the stationary form above. The constant size distribution leads to output per industry growing at rate $\gamma_{k}$, since output is labor input times $\gamma_{k}^{v}$. Output and consumption grow at the same rate, verifying that such an equilibrium path is possible.

The return to building a plant exactly equals the cost of the unit of capital it takes to create it. The equilibrium $p_{0}$ is calculated so that the free entry condition is satisfied; i.e., $W(0)=1$. The equilibrium for industry $i$ can be solved by guessing a $p_{0}$, solving the 
plant's problem, and then raising or lowering $p_{i}$, depending on whether profits are too low or too high, respectively. The results of some computations for a parameterized version are the subject of the following section.

\section{Increasing Growth and the Size Distribution}

The purpose of this model is to see how the size distribution differs across different rates of growth of embodied technological change. In the model, each industry is in a steady state growing at rate $\gamma_{i}$ in output terms. In this section, I compare steady state size distributions for different growth rates $\gamma_{i}$. A technological revolution is interpreted as a one time, permanent change in $\gamma_{i}$ for a single industry, leaving average growth unchanged, and therefore not affecting the general equilibrium except for industry $i$. The data suggest that technological revolutions lower average size and make the size distribution less variable. Here I ask whether the long run steady state for various $\gamma$ has this feature: Does higher $\gamma$ lead to a smaller average plant size and less variable plant size in the stationary distribution of plants?

In terms of variance, $\gamma$ has two effects. On the one hand, high $\gamma$ increases the disparity between plants with different vintages. On the other hand, increases in $\gamma$ tend to lead to plants choosing to update sooner, therefore being bunched closer to each other in terms of vintage, and hence less varied in terms of their labor choice. The effects at work on average size are taken up next.

\section{A. Average Size and Increasing Growth: Myopia and No Discounting}

Two extreme cases, $r=0$ and $r=\infty$, help explain the forces at work in the model. First, consider a case where $r=0$, which will occur if $\delta=1$. Of course, with an infinite horizon, this is not a well defined optimization problem. Therefore consider a $T$ period case. 
Define $\lambda_{b}=1-h^{n}\left(\sigma_{0}^{2}\right)$. If $p$ is falling at a constant rate $\gamma$, for any age $b$ I have that

$$
l^{*}(b ; p)=\left(\frac{p \alpha \lambda_{b}}{\gamma^{b}}\right)^{\frac{1}{1-\alpha}}
$$

where $p$ is the initial price. Profits are

$$
\pi(b ; p)=\kappa\left(\frac{p \lambda_{b}}{\gamma^{b}}\right)^{\frac{1}{1-\alpha}}
$$

where $\kappa=\alpha^{\frac{\alpha}{1-\alpha}}-\alpha^{\frac{1}{1-\alpha}}$.

The free entry condition is ${ }^{12}$

$$
\sum_{t=0}^{b^{*}} \frac{T}{b^{*}+1} \pi(t ; p)=E
$$

The plant spends a fraction $\frac{1}{b^{*}+1}$ of its $T$ period life in a given state. Rearranging (11), we have

$$
\sum_{t=0}^{b^{*}} \frac{1}{b^{*}+1}\left(\frac{\lambda_{t}}{\gamma^{t}}\right)^{\frac{1}{1-\alpha}}=\frac{E}{\kappa T p^{\frac{1}{1-\alpha}}}
$$

Average size in this industry is

$$
\sum_{t=0}^{b^{*}} \frac{1}{b^{*}+1} l^{*}(t ; p)=\alpha^{\frac{1}{1-\alpha}} p^{\frac{1}{1-\alpha}} \sum_{t=0}^{b^{*}} \frac{1}{b^{*}+1}\left(\frac{\lambda_{t}}{\gamma^{t}}\right)^{\frac{1}{1-\alpha}}=\frac{\alpha E}{(1-\alpha) T} .
$$

The last equality comes from (12) and combining $\kappa$ with $\alpha^{\frac{1}{1-\alpha}}$. When $r=0$, there is no effect on average size from changing $\gamma$; it is just a constant that depends on $\alpha, E$, and $T$.

\footnotetext{
${ }^{12} \mathrm{I}$ am implicitly assuming $T$ is divisible by $b^{*}+1$. This approximation is fine if $T$ is large.
} 
On the other hand, consider the case where $\delta=0$. In that case, $p$ is independent of $\gamma$. For a fixed $b^{*}>0$, the average size falls, since every vintage other than the frontier is less productive, and therefore marginal revenue product is lower. On the other hand, higher $\gamma$ tends to lower $b^{*}$, which can have the effect of raising average size by moving plants closer to the technological frontier. The dominant effect is uncertain and, it turns out, can be either.

In the case where $\delta$ is between zero and one, these forces show up in the equilibrium effects of $\gamma$. The detrended price in the industry with high growth, $p_{0 i}$, is larger than that in the low growth industry. This can be seen by looking at the detrended problem in (8). For all industries, entrants' profits are zero. When $\gamma$ is high, for any $p_{0}$, profits are lower. Therefore $p_{0}$ must be higher in the case of higher $\gamma$ if zero profits are to be attained. This force is tending to make establishments larger as $\gamma$ increases, since it increases the marginal revenue product of labor. This general equilibrium effect is an important complication that keeps the model from being able to be solved analytically. In order to explore the effect of a technological revolution, the quantitative implications of the model are explored for a set of parameters chosen to reasonably replicate some features of the U.S. data.

\section{B. Benchmark Parameterization}

The time period is taken to be a year. The discount factor is chosen so that the interest rate is 4 percent. The curvature parameter $\alpha$ is chosen so that labor's share is .66. Choosing $E$ is purely a normalization; increasing $E$ simply scales up all the plant sizes. Here $E$ is taken to be one; only relative changes in average size and size variability are considered in the simulations.

The final parameters to choose are $\sigma_{\varepsilon}^{2}$ and $\sigma_{0}^{2}$. To determine $\sigma_{0}^{2}$ (entrants' variance), 
consider the ratio of productivity at the end of the learning process to that at the beginning. Learning studies (as summarized, for instance, in Jovanovic and Nyarko (1996)) indicate that productivity roughly doubles over the learning curve:

$$
\frac{1}{1-\sigma_{0}^{2}}=2
$$

so $\sigma_{0}^{2}=.5$.

For $\sigma_{\varepsilon}^{2}$, a value of 2 is used. This has two features which are empirically plausible. First is that such a value implies significant learning for the first 5 to 6 years of a new plant's operation, consistent with data in Bahk and Gort (1993). Furthermore, the ratio of second year productivity to first,

$$
\frac{1-h_{1}\left(\sigma_{0}^{2}\right)}{1-\sigma_{0}^{2}}
$$

is in line with learning studies of manufacturing such as those summarized in Auerswald et al. (1998). These learning studies suggest that the rate of learning is about $20 \%$ per doubling of cumulative output. The ratio above can be thought of as the productivity of the last unit in the first year compared to a unit in the second year; since plants grow in this formulation, cumulative output doubles sometime during the second year. Therefore, the statistic above should be set to 1.2 , implying that $\sigma_{\varepsilon}^{2}=2$.

Since the results are not ones which can be proven, but rather depend on parameters, the following section reports not only the outcome for the benchmark parameterization, but also for a variety of other parameters. 


\section{Simulation Results}

The following results are for the steady state size distribution for industries growing at various rates, given the benchmark parameterization. Everything is reported as a percentage of the statistic for an industry with $\gamma=1.01$, since the level of the variables is simply a normalization. The rate 1.01 reflects the average rate of progress for the industries not experiencing a significant increase in their growth rate, i.e., the industries that were not in the top quartile for $\beta_{i}^{T}$.

$\begin{array}{ccc}\gamma & \text { Mean Plant Size } & \text { St.Dev. of Plant Size } \\ 1.01 & 1 & 1 \\ 1.04 & .96 & .81 \\ 1.10 & .96 & .62 \\ 1.15 & .96 & .48\end{array}$

The model predicts a very sharp decline in variance as a result of the higher rate of technological progress. Going from one percent growth to 15 percent growth more than halves the standard deviation of plant size. The reason is that the number of vintages in operation, $b^{*}$, falls dramatically. When $\gamma=1.01$, the plant upgrades every 15 years; when $\gamma=1.15$, it upgrades every other year. Of course, vintage choice is the only source of variation here. In a model with another source of variation unrelated to $\gamma$, the effect would be less in percentage terms. For instance, a shock to the plant's productivity along the lines of the one studied in Hopenhayn (1992) would provide another source of size variability. The important point here is that technology adoption can be a strong force toward uniformity in plant size as the 
growth rate rises, since it is difficult to be both experienced and "high-tech."

In terms of size, the effect is smaller. If every hundredth for $\gamma$ is examined from 1.01 to 1.15 , some small non-monotonicities emerge in the average size; that is, sometimes a one percent increase in $\gamma$ actually slightly increases the size of plants. However, the clear trend is downward. These non-monotonicities, though, point to some of the complicated nonlinear effects that are were discussed above.

Since there are a variety of effects at work, it is useful to check some other parameter values to ensure that the results presented are not too dependent on the exact parameterization. I take up each parameter in turn.

One important parameter in the model is $\sigma_{0}^{2}$, since it determines the relative efficiency of new and old vintages due to learning. The benchmark was that productivity doubled from the start to the end of the learning curve. I consider two possibilities: even more learning, where productivity triples over the learning curve $\left(\sigma_{0}^{2}=.66\right)$, and a smaller learning curve, where initial variance is cut in half $\left(\sigma_{0}^{2}=.25\right)$. Again, only relative levels are considered, so the statistics are all percentages of the value that occurs for that parameter value when $\gamma=1.01$.

\begin{tabular}{ccccc} 
& \multicolumn{2}{c}{$\sigma_{0}^{2}=.66$} & \multicolumn{2}{c}{$\sigma_{0}^{2}=.25$} \\
$\gamma$ & Mean & St.Dev. & Mean & St.Dev. \\
1.01 & 1 & 1 & 1 & 1 \\
1.04 & .98 & .81 & .98 & 0 \\
1.10 & .95 & .73 & .98 & 0 \\
1.15 & .97 & .71 & .98 & 0
\end{tabular}

When the learning problem is trivial $\left(\sigma_{0}^{2}=0\right)$, of course every plant is at the frontier 
every period, and so it is easy to see that $\gamma$ has no effect on the mean or variance of plant sizes; the variance is zero. When $\sigma_{0}^{2}$ is lowered to .25 , this incentive becomes stronger: for growth rates 1.04 and above, plants upgrade every period, forfeiting any learning possibilities. The size distribution remains unchanged in this range. Otherwise, the results are qualitatively similar to the results of the benchmark parameterization. The higher is $\sigma_{0}^{2}$, the more important is the learning, and plants hold onto a given technology longer. The effect of $\gamma$ on the variance is felt more strongly for low $\gamma$ when $\sigma_{0}^{2}$ is small.

Empirically, the speed of learning varies across tasks, so it is useful to consider a variety of values of $\sigma_{\varepsilon}^{2}$. The model is computed for values of $\sigma_{\varepsilon}^{2}$ fifty percent higher and lower than the benchmark. When $\sigma_{\varepsilon}^{2}=3$, the noise in the plant's problem is greater, and therefore learning is slower, since each observation on $\theta+\varepsilon$ is less informative. When $\sigma_{\varepsilon}^{2}=1$, on the other hand, the signal is more informative, and learning is faster.

\begin{tabular}{ccccc} 
& \multicolumn{2}{c}{$\sigma_{\varepsilon}^{2}=3$} & \multicolumn{2}{c}{$\sigma_{\varepsilon}^{2}=1$} \\
$\gamma$ & Mean & St.Dev. & Mean & St.Dev. \\
1.01 & 1 & 1 & 1 & 1 \\
1.04 & .97 & .52 & .97 & .93 \\
1.10 & .98 & .17 & .95 & .82 \\
1.15 & .95 & 0 & .95 & .67
\end{tabular}

The speed of learning has very little effect on the results for average size. In terms of variance, faster learning (lower $\sigma_{\varepsilon}^{2}$ ) makes the effect of $\gamma$ on size variability smaller. The results suggest, then, that a vintage model with learning can generate a downward relationship 
between the growth rate and both the mean and variance of plant size. ${ }^{13}$

\section{Learning vs. Fixed Cost of Upgrading}

The key to the model's ability to generate the appropriate direction of change in average size and variability in response to a growth rate increase is due to the vintage flavor of the model as well as the learning. Without the learning component, the model would not generate any change in the variability of sizes, since all plants would be right at the frontier. The fact that there is a cost of upgrading is essential, and the fact that the cost is paid in terms of temporarily lowered productivity is also important.

Suppose, for instance, that the cost of upgrading were simply some fixed cost $F$ of upgrading, so that the maximum productivity, and hence size, was attained by plants that just upgraded. The problem is otherwise the same as above, but with $\lambda_{t}=1$ always. With this sort of cost of upgrading, faster technological progress leads to an extra force that makes establishments larger. The industry economizes on the increased need to pay the cost of upgrading by paying it for fewer establishments.

To see that effect, consider again the case where $r=0$, as was done previously. The free entry condition becomes

$$
\sum_{t=0}^{b^{*}} \frac{T}{b^{*}+1} \pi(t ; p)=E+\frac{T}{b^{*}+1} F .
$$

If $b^{*}$ is constant, the earlier analysis holds, and $\gamma$ does not affect average size. However, any time that $b^{*}$ decreases, i.e., any time that updates are more frequent, it is as if the fixed cost

\footnotetext{
${ }^{13}$ In addition, the model was simulated with other values for $\alpha$ (returns to scale) and $\beta$ (the discount factor). Neither proved crucial to the results, and both are available upon request.
} 
of entry is higher. This has the effect, as can be seen from the algebra above, of increasing plant size. As $\gamma$ increases, it is easy to see that $b^{*}$ falls. This tends to make plants larger, so that this increased cost of retooling is paid at fewer plants. When the cost is paid in terms of productivity, though, the cost does not depend on the number of plants that upgrade, but on the output of those plants, and this effect is no longer present.

\section{Summary}

There is evidence that technological revolutions are associated with decreasing establishment size and reduced variability of the size distribution. Many theories concerning the linkage between size and growth have focused on the innovative "efficiency" of small establishments compared to big ones. Here the causality is reversed, i.e., from the growth rate to the optimal size. The link between the size and variance of the U.S. manufacturing size distributions brings to light an additional fact to which models of size and growth might strive.

The model has two key ingredients. The first is a vintage structure, where the age of capital is an important determinant of plant size. The second is learning. Learning by doing counteracts the incentive to upgrade every period. It is clear that in a model where adoption is important, increased growth leads to a lower average age of technology, a bunching near the technological frontier. This is a strong force reducing the variance of sizes. On the other hand, when new technologies take time to learn, this bunching changes the average organizational capital of the plants and can lower the average size of plants.

There are several ways to compare the results to the literature. One is as a contribution to the substantial literature on the relationship between innovation and the scale of 
production. Here, the amount of "innovative activity," measured by productivity growth, affects the scale of plants. This is a complementary view to the idea that size may affect innovation; the relationship is likely generated by forces in both directions.

Given the fact that there has been dramatic downsizing of U.S. manufacturing plants, this paper provides an explanation for a portion of this change. Clearly there are many forces behind the fall in plant size, but one could be the fact that some industries have experienced changes that have left them with smaller and less variable sizes. Moreover, the data show that while a substantial number of revolutions have occurred, few industries have had precipitous falls in their rates of productivity growth. It seems that more industries have entered revolutions than have ended revolutions.

Understanding the changes in the U.S. manufacturing size distribution appears to be an important part of understanding the organization of production and should be a topic for future research. Some authors (for instance, Greenwood and Yorukoglu (1997)) have suggested that the early 1970s marked the start of an economy-wide technological revolution resulting from information technology. In the aggregate data, a clear downward movement in both size and variance can be seen right around the time that this technological revolution is suggested to have happened. Understanding the size distribution can help uncover whether there is a link between these facts. 


\section{References}

[1] Acs, Zoltan and David Audretsch (1990). Innovation and Small Firms. Cambridge: MIT Press.

[2] Argote, L. and Epple, D. (1990). "Learning Curves in Manufacturing," Science, Vol. 247, pp. 920-924.

[3] Auerswald, P., Kauffman, S., Lobo, J. and Shell, K. (1998). "The Production Recipe Approach to Modeling Technological Innovations: An Application to Learning by Doing," CAE Working Paper \#98-10, Cornell University.

[4] Bahk, B. and Gort, M. (1993). "Decomposing Learning by Doing in New Plants," Journal of Political Economy 101, pp. 561-83.

[5] Baily, Martin Neil, Bartelsman, Eric J., and Haltiwanger, John (1996). "Downsizing and Productivity Growth: Myth or Reality?" in Mayes, David G., ed., Sources of Productivity Growth. Cambridge: Cambridge University Press, pp. 263-288.

[6] Bartelsman, Eric and Wayne Gray (1996). "The NBER Manufacturing Productivity Database," NBER Technical Paper 205.

[7] Doms, Mark and Timothy Dunne (1998). "Capital Adjustment Patterns in Manufacturing Plants," Review of Economic Dynamics 1, pp. 409-429.

[8] Dulberger, Ellen R. (1989). "The Application of a Hedonic Model to a Quality-Adjusted Price Index for Computer Processors," in Technology and Capital Formation, Dale W. Jorgenson and Ralph Landau, eds., MIT Press. 
[9] Gowrisankaran, G. and Mitchell, M. (2000). "Downsizing and Wages: US manufacturing 1977-94," manuscript, University of Minnesota.

[10] Greenwood, Jeremy, Zvi Hercowitz, and Per Krusell (1997). "Long-Run Implications of Investment-Specific Technological Change," American Economic Review 87, pp. 342-62.

[11] Greenwood, J. and B. Jovanovic (1999). "The IT Revolution and the Stock Market," AER Papers and Proceedings 89, pp. 116-122.

[12] Greenwood, J. and Mehmet Yorukoglu (1997). "1974," Carnegie-Rochester Conference Series on Public Policy, Vol. 46, p. 49.

[13] Hopenhayn, Hugo (1992). "Entry, Exit, and Firm Dynamics in Long Run Equilibrium," Econometrica 60, 1127-1150.

[14] Jovanovic, Boyan, and Yaw Nyarko (1996). "Learning By Doing and the Choice of Technology," Econometrica 64, 1299-1310.

[15] Prescott, Edward (1972). "The Multi-Period Control Problem Under Uncertainty," Econometrica 40, 1043-1058.

[16] Scherer, F.M. (1980). Industrial Market Structure and Performance. Boston: Houghton Mifflin Co.

[17] Wilson, R. (1975). "Informational Economies of Scale," Bell Journal of Economics 6, 184-195. 